\title{
Diurnal blood pressure variation and cardiovascular prognosis in a community-based study of Ohasama, Japan Diurnal variations in blood pressure: clinical implications and pathogenesis
}

\author{
Hirohito Metoki ${ }^{1,2}$, Takayoshi Ohkubo ${ }^{3}$ and Yutaka Imai ${ }^{1}$
}

The introduction of 24-h ambulatory blood pressure (BP) monitoring has enabled BP evaluations at specific times of the day. Associations between diurnal BP variation and cardiovascular prognosis have been investigated in the Ohasama study, which is an epidemiological survey of hypertension using ambulatory and home BP monitoring that has been ongoing since 1985 in the general population of Ohasama, a town located in northern Japan. A diminished nocturnal decline in systolic BP was associated with a greater common carotid intima-media thickness as well as a higher risk of cardiovascular morbidity and mortality, especially the risk for cerebral infarction. The consumption of large amounts of alcohol was associated with a higher morning pressor surge. A large nocturnal decline in BP and a large morning pressor surge were both associated with a risk of cerebral hemorrhage. Ambulatory BP monitoring provides not only static, but also dynamic information about BP that should be considered to ensure effective management of hypertension and cardiovascular diseases.

Hypertension Research (2010) 33, 652-656; doi:10.1038/hr.2010.70; published online 30 April 2010

Keywords: ambulatory blood pressure monitoring; morning pressor surge; nocturnal decline in blood pressure

\section{INTRODUCTION}

High blood pressure (BP) is associated with target-organ damage and a poor cardiovascular prognosis. The introduction of 24-h ambulatory BP monitoring has enabled BP to be evaluated at specific times of day. A single $\mathrm{BP}$ value obtained using an ambulatory device on rising in the morning is a better discriminator of future cardiovascular events than the mean of three measurements taken under standardized conditions in a hospital or clinic. ${ }^{1}$ Several recently proposed indices of circadian $\mathrm{BP}$ variation might be relevant to the diagnosis and management of hypertension with special reference to target-organ damage and prognosis. The present review describes diurnal BP variation and cardiovascular prognosis from the results of the Ohasama study, which is an epidemiological survey of hypertension based on ambulatory BP monitoring that was started in 1985 among the general population of Ohasama, a town located in northern Japan.

\section{STUDY POPULATION}

Ohasama had a population of 9400 in 1985. We have obtained ambulatory BP data over the past 20 years by monitoring over 3000 inhabitants aged $\geqslant 20$ years, as well as outcomes and information about risk factors and predictors. To prospectively investigate the association between BP levels and subsequent risk of outcomes, we excluded individuals aged $<40$ years at the time of ambulatory BP monitoring because death or stroke occurrence was less frequent among younger persons. Thus, several indexes of BP obtained by ambulatory monitoring were prospectively analyzed among 1542 inhabitants of Ohasama aged $\geqslant 40$ years.

\section{NOCTURNAL DECLINE IN BP}

BP generally increases on awakening in the morning and falls while asleep during the nighttime. This circadian variation in BP is regulated by the autonomic nervous and endocrine systems, and modified by several factors such as physical and mental activities as well as environmental stressors. Nocturnal BP usually falls 10-20\% from the diurnal value and is referred to as nocturnal dipping. However, nocturnal dipping is attenuated or disappears under several pathophysiological conditions and persons with this phenomenon are referred to as 'non-dippers.' Those with higher nocturnal BP than the diurnal value are referred to as 'inverted dippers' or 'risers.' A person with a large nocturnal decline in BP is defined as an 'extreme

${ }^{1}$ Department of Clinical Pharmacology and Therapeutics, Tohoku University Graduate School of Pharmaceutical Sciences and Medicine, Sendai, Japan; ${ }^{2}$ Department of Medical Genetics, Tohoku University Graduate School of Pharmaceutical Sciences and Medicine, Sendai, Japan and ${ }^{3}$ Department of Planning for Drug Development and Clinical Evaluation, Tohoku University Graduate School of Pharmaceutical Sciences and Medicine, Sendai, Japan

Correspondence: Dr Y Imai, Department of Clinical Pharmacology and Therapeutics, Tohoku University Hospital, 1-1 Seiryo-cho, Aoba-ku, Sendai, Miyagi 980-8574, Japan. E-mail: rinsyo@mail.pharm.tohoku.ac.jp

Received 7 February 2010; revised 10 March 2010; accepted 28 March 2010; published online 30 April 2010 
dipper.' However, nocturnal BP remains normal or high among hypertensive patients. Therefore, 'extreme dippers' among hypertensive patients are equivalent to 'diurnal risers.' Such disordered circadian BP variations are associated with a poor cardiovascular prognosis $^{3-6}$ and are regarded as targets for antihypertensive therapy.

The decline in nocturnal BP was calculated in the Ohasama study as follows: nocturnal decline in BP $(\%)=($ daytime $\mathrm{BP}$-nighttime BP) $\times 100 /$ daytime BP. We classified the subtypes of nocturnal decline in BP as follows: extreme dipper (20\% nocturnal decline in BP from diurnal value), dipper (10-19\% nocturnal decline in BP), non-dipper (0-9\% nocturnal decline in BP) and riser (0\% nocturnal decline in BP or nocturnal elevation).

\section{NOCTURNAL DECLINE IN BP AND CARDIOVASCULAR MORTALITY}

We reported the association between ambulatory BP and cardiovascular prognosis in 1997. That report describes that ambulatory BP predicted mortality more effectively than casual screening of $\mathrm{BP}$ during a mean follow-up period of 5.1 years. $^{7}$ During the same observation period, the mortality risk was highest among risers, followed by non-dippers. Mortality rates did not differ between extreme dippers and dippers. This relationship in both treated and untreated individuals was more remarkable for cardiovascular, than for non-cardiovascular mortality, and was not changed after adjustment for 24-h, daytime and nighttime BP levels. ${ }^{8}$ Follow-up for a mean of 9.2 years showed that a diminished nocturnal decline in BP was associated with a risk for cardiovascular mortality, which was independent of the overall BP load during a 24-h period. ${ }^{9}$

\section{NOCTURNAL DECLINE IN BP AND RISK OF STROKE}

Analysis of data over a mean follow-up period of 10.4 years revealed no consistent association between dipping profile and the risk of total stroke. The data did not fit a linear model; the relative hazard per 1 s.d. increase of nocturnal decline in BP was 1.1 (95\% CI, 0.8-1.4, $P=0.7)$. The risk for cerebral infarction was significantly higher among individuals with a diminished nocturnal decline (risers and nondippers) than among those with a decline of $\geqslant 10 \%$ (dippers and extreme dippers). The relative hazard among individuals with a diminished nocturnal decline was 1.6 (95\% CI, 1.0-2.5, $P=0.04$ ). Extreme dippers had 2.7-fold higher risk (95\% CI, 1.1-6.4, $P=0.02)$ of cerebral hemorrhage than those with a nocturnal decline of $<20 \%$ (dippers, non-dippers and risers).

\section{MORNING BP SURGE}

BP that abruptly increases around awakening in the morning is called the 'morning pressor surge.'10,11 The association between morning BP surge and cardiovascular disease has received focus because cardiovascular events occur more frequently in the morning ${ }^{12-14}$ and a mean follow-up of 20 months has revealed that elderly patients with a large morning pressor surge have a threefold higher risk of stroke. ${ }^{15}$

The amplitude of the morning pressor surge in the Ohasama study was defined based on earlier findings ${ }^{11}$ as follows: morning pressor surge in systolic blood pressure $(\mathrm{SBP})=2-\mathrm{h}$ mean SBP after waking-2-h mean SBP before waking.

The morning pressor surge can also be calculated by a method that generates the 'sleep-trough' morning pressor surge, ${ }^{15}$ which is calculated as follows: sleep-trough morning pressor surge in $\mathrm{SBP}=2-\mathrm{h}$ mean SBP after waking-lowest SBP defined as mean BP of three readings centered on the lowest nighttime reading.
An association between morning pressor surge and the incidence of total stroke $(n=128)$ and of cerebral infarction $(n=86)$ was not identified during a 10.4-year follow-up. However, the risk for cerebral hemorrhage $(n=27)$ was significantly high in the fifth quintile group with a morning pressor surge amplitude of $25 \mathrm{~mm} \mathrm{Hg}$ (RH, 4.0; 95\% CI, 1.1-14.6, $P=0.04$ ), when the second quintile of the morning pressor surge (amplitude $3-11 \mathrm{~mm} \mathrm{Hg}$ ) was set as the reference category. ${ }^{16}$ The predictive value of the sleep-trough morning surge was similar to that of the sleeping-to-waking morning surge in the same population. ${ }^{16}$

The International Database of Ambulatory Blood Pressure in relation to Cardiovascular Outcome has recently been established. ${ }^{17,18}$ A morning surge in BP exceeding the 90th percentile in this database was a significant and independent predictor of mortality and cardiovascular events even after correcting the night-to-day BP ratio, the 24-h BP level and other covariables. ${ }^{19}$ Moreover, consistent with our earlier findings, ${ }^{16}$ Asians with a morning surge in the top decile were at a significantly higher risk for hemorrhagic stroke $(n=51$; HR [95\% CI], 2.28 [1.09-4.26], $P=0.03$ ), but not for ischemic stroke $(n=127 ; \mathrm{HR}, 1.41[0.67-2.98], P=0.37)$, than those with a lower morning surge.

\section{BP AT A SPECIFIC TIME OF DAY}

Although the predictive value of BP increases with increasing numbers of measurements, ${ }^{20,21} \mathrm{BP}$ values obtained at different times of the day (nighttime, morning and daytime) have not been compared with values obtained by the same number of measurements. A simple calculated mean of the BP values recorded every $30 \mathrm{~min}$ during the nighttime $(8 \mathrm{~h})$ generates 16 values; similarly, a simple mean of the daytime (16h) BP values recorded every $30 \mathrm{~min}$ yields 28 values. Therefore, if the predictive power of BP obtained during the daytime was more powerful than taken during the nighttime, it could reflect the larger number of measurements taken during the daytime.

The means of four BP readings obtained every $30 \mathrm{~min}$ for two consecutive hours in a day (moving averages) during the Ohasama study were defined as '2h-BP' (see Figure 1 ). ${ }^{22}$ When readings were omitted because of missed and/or artifactual measurements, calculations were based on the remaining readings (minimum of one) obtained during the 2 - $\mathrm{h}$ period. The $2 \mathrm{~h}-\mathrm{BP}$ allows a comparison of

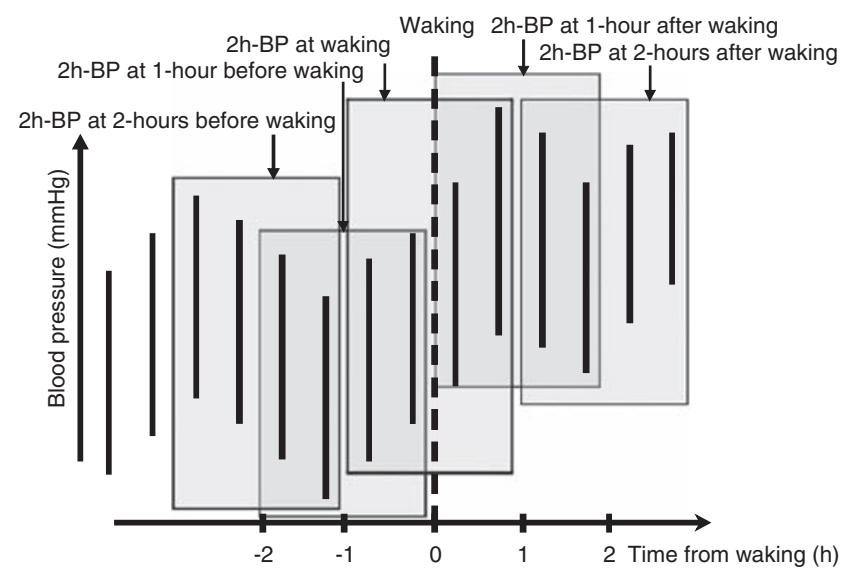

Figure 1 Definition of moving average of 2-h SBP/2-h DBP. Means of four SBP/DBP readings obtained over two consecutive daytime hours (moving averages) are defined as $2 \mathrm{~h}-\mathrm{SBP} / 2 \mathrm{~h}-\mathrm{DBP}$. Horizontal line indicates time (hours) from waking. Vertical line shows BP $(\mathrm{mm} \mathrm{Hg})$. Reproduced from our earlier article22 with permission from the Lippincott Williams \& Wilkins. 
the predictive value of BP taken at different times using the same number of BP measurements.

\section{BP AT A SPECIFIC TIME OF DAY AND CARDIOVASCULAR MORTALITY}

When nighttime and daytime SBP values were simultaneously included in the same Cox model, only nighttime BP significantly predicted cardiovascular mortality risk from the 10.8-year follow-up data. We concluded that the relationship between ambulatory SBP and cardiovascular mortality is not $\mathrm{U}$ - or J-shaped, and that the prognostic value of BP during the nighttime is better than that during the daytime. ${ }^{23}$ We applied $2 \mathrm{~h}-\mathrm{BP}$ to evaluate the relevance of BP at a particular time of day to the risk of stroke mortality. Total cerebrovascular and cardiovascular mortality risk was significantly associated with elevated $2 \mathrm{~h}$-BP recorded during the night and early morning. Hemorrhagic stroke mortality was significantly associated with elevated daytime $2 \mathrm{~h}-\mathrm{BP}$. The mortality of cerebral infarction and heart disease was significantly associated with elevated nighttime $2 \mathrm{~h}-\mathrm{BP}^{22}$

\section{BP AT A SPECIFIC TIME OF DAY AND RISK OF STROKE}

The risk of stroke incidence in the Ohasama study was more closely associated with daytime, than with nighttime BP over a mean followup of 6.4 years. $^{24}$

Using $2 \mathrm{~h}-\mathrm{BP}$ to evaluate the relevance of $\mathrm{BP}$ taken at a specific time of day to determine the risk of stroke morbidity showed that risk for total stroke incidence was significantly associated with systolic 2h-BP values (2h-SBPs) throughout the day (Figure 2). Risk for incidence of intracerebral hemorrhage was significantly associated with elevated daytime $2 \mathrm{~h}$-SBPs, but less so with nighttime $2 \mathrm{~h}$-SBPs (Figure 3a). Risk for the incidence of cerebral infarction was significantly associated with nighttime $2 \mathrm{~h}-\mathrm{SBPs}$, but less so with daytime 2h-SBPs (Figure $3 \mathrm{~b}$ ).

\section{DIURNAL BP VARIATION AND TARGET-ORGAN DAMAGE}

Cross-sectional analyses regarding target-organ damage were performed during the Ohasama study. Nighttime BP was most closely associated with carotid artery alterations among values for daytime, nighttime and casual BP. Although a morning pressor surge was not associated with carotid artery alterations, a diminished nocturnal decline in SBP was associated with common carotid intima-media thickness after adjustment for confounding factors. ${ }^{25}$ Daytime and nighttime BP values were both associated with silent cerebrovascular lesions, whereas casual BP in the same population was not. ${ }^{26}$

\section{FACTORS ASSOCIATED WITH DIURNAL BP VARIATION}

\section{Alcohol consumption and diurnal BP variation}

We found, using $2 \mathrm{~h}-\mathrm{BP}$, that BP rapidly increased before awakening and that morning BP was higher among Ohasama inhabitants who consumed alcohol. The morning pressor surge was significantly higher among those who consumed large amounts of alcohol than in those who consumed none, whereas alcohol consumption status was not significantly associated with the magnitude of the nocturnal decline in $\mathrm{BP}^{27}$

\section{Genetic polymorphisms and diurnal BP variation}

Daytime SBP and diastolic blood pressure (DBP) values were higher in individuals with the $\mathrm{C}$ allele in the angiotensin II type 1 receptor gene $\mathrm{A} / \mathrm{C}^{1166}$ polymorphism $(130.5 \pm 14.0 / 77.4 \pm 8.3 \mathrm{~mm} \mathrm{Hg})$ than in those with the AA genotype $(127.7 \pm 13.6 / 75.8 \pm 8.3 \mathrm{~mm} \mathrm{Hg}, P=0.03 / 0.04)$, although the difference was not statistically significant after adjusting for age, gender, body mass index and smoking status. ${ }^{28}$ Nighttime BP values were significantly lower among individuals with the MM genotype in the angiotensinogen M235T polymorphism than in those with the $\mathrm{T}$ allele $(105.2 \pm 13.0 / 60.1 \pm 6.9$ vs. $110.6 \pm 13.3 /$ $63.6 \pm 7.8 \mathrm{~mm} \mathrm{Hg}, P=0.04 / 0.02)$. The nocturnal decline in $\mathrm{BP}$ was significantly larger among those with the MM genotype than with the Tallele (17.4/19.8 vs. $13.5 / 16.2 \mathrm{~mm} \mathrm{Hg}, P=0.004 / 0.01) .{ }^{29}$ The nocturnal decline in $\mathrm{BP}$ was significantly greater among individuals with a homozygous CC aldosterone synthase gene (CYP11B2) C-334T polymorphism than in others $(15.4 \% / 17.7 \%$ vs. $13.3 \% / 16.1 \%, P=0.007 /$ 0.03 ), although 24 -h ambulatory BP levels did not significantly differ among the genotypes. ${ }^{30}$

We recently focused on the (pro)renin receptor gene. Although casual BP was not associated, 24-h, daytime and nighttime SBP and DBP values were significantly higher among male carriers of the IVS5+169T rather than the $\mathrm{C}$ allele of the (pro)renin receptor gene. BP values did not significantly differ among the three genotypes of female IVS5+169C $>$ T carriers. ${ }^{31}$

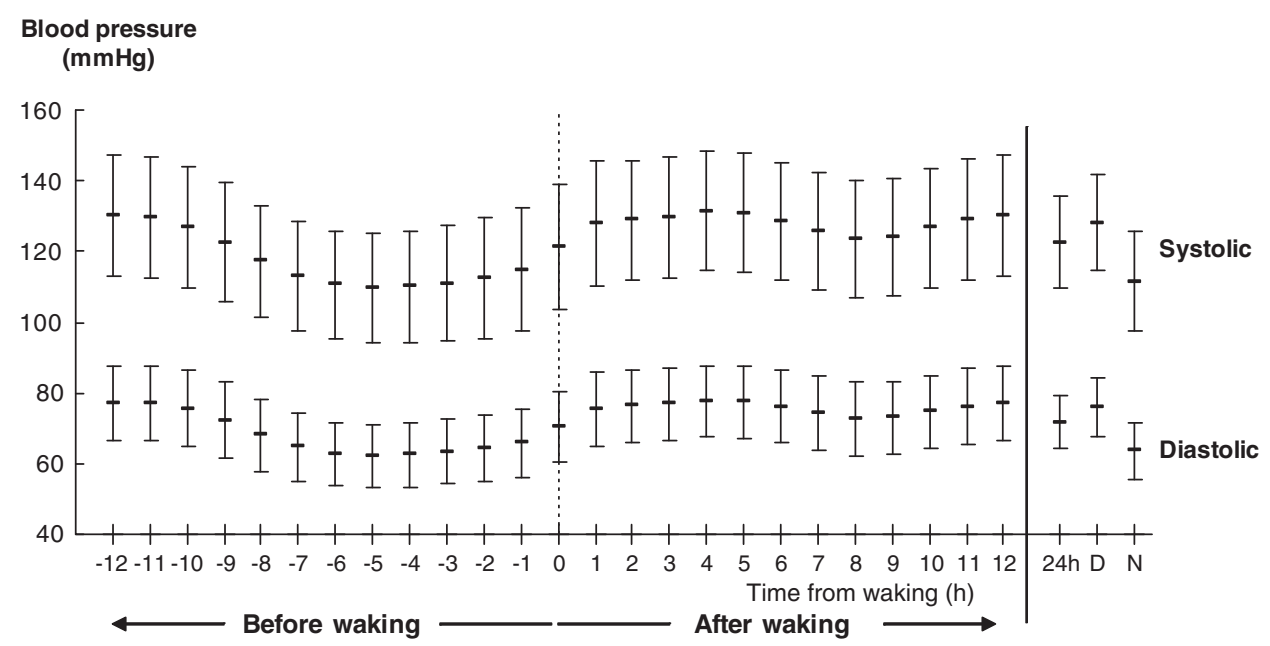

Figure 2 Circadian BP variation of SBP and DBP using 2-h SBP/2-h DBP. Left panel: 2-h moving averages of SBP and DBP over 24-h period based on time (hours) from waking. Right panel: 24-h, daytime and nighttime mean BP values are shown as $24 \mathrm{~h}, \mathrm{D}$ and N, respectively. 
a Incidence of intracerebral hemorrhage

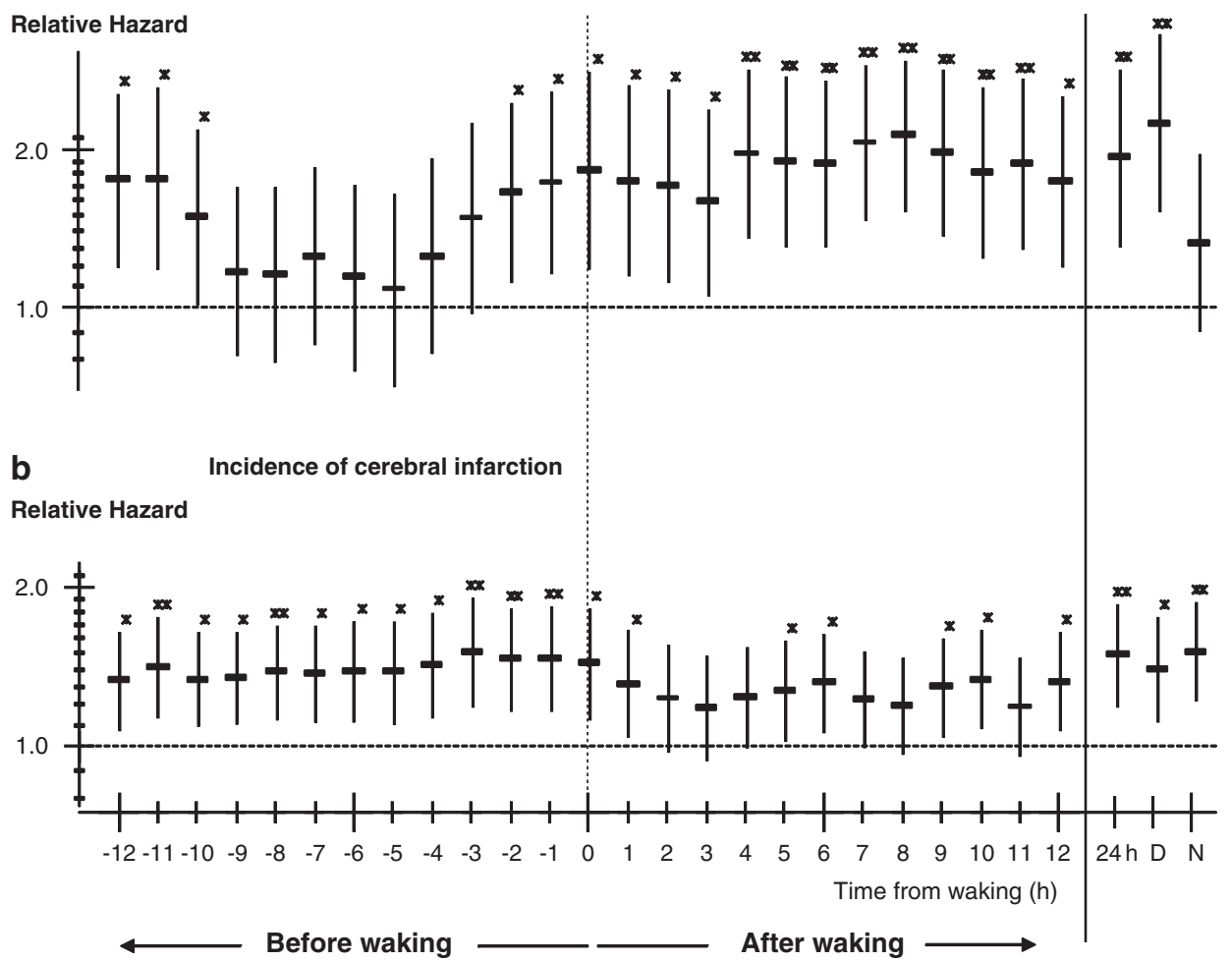

Figure 3 Relative hazard for incidence of stroke subtypes per 1-s.d. elevation of SBP values. Relative hazards and 95\% confidence intervals for incidence of (a) hemorrhage stroke and (b) cerebral infarction per 1-s.d. elevation of SBPs over a mean follow-up of 10.2 years in Ohasama, Japan. Left panel: Numbers indicate 2-h moving averages of SBP over 24-h period. Right panel: $24 \mathrm{~h}, \mathrm{D}$ and $\mathrm{N}$ on the right slide panel indicate 24 -h, daytime, and nighttime mean SBP values, respectively. Each analysis was adjusted for age, gender, smoking status, antihypertensive medication, history of heart disease, hypercholesterolemia and diabetes mellitus. ${ }^{*} P<0.05 ;{ }^{*} P<0.002$ (Bonferroni's adjustment).

\section{CONCLUSION}

The results of the Ohasama study show that ambulatory BP values are uniquely associated with cardiovascular diseases and their prognosis. Ambulatory BP values provide not only static, but also dynamic information about BP that is applicable to the effective management of hypertension and cardiovascular diseases.

\section{ACKNOWLEDGEMENTS}

We are grateful to all collaborating mentors, colleagues, foundations and individuals.

1 Gosse P, Cipriano C, Bemurat L, Mas D, Lemetayer P, N'Tela G, Clementy J. Prognostic significance of blood pressure measured on rising. J Hum Hypertens 2001; 15: 413-417.

2 Nishiyama A, Imai Y, Ohkubo T, Tsuji I, Nagai K, Kikuchi N, Kato J, Sekino M, Aihara A, Kikuya M, Satoh H, Hisamichi S. Determinants of circadian blood pressure variation: a community-based study in Ohasama. Tohoku J Exp Med 1997; 183: 1-20.

3 Staessen JA, Thijs L, Fagard R, O'Brien ET, Clement D, de Leeuw PW, Mancia G, Nachev C, Palatini P, Parati G, Tuomilehto J, Webster J. Predicting cardiovascular risk using conventional vs ambulatory blood pressure in older patients with systolic hypertension. systolic hypertension in Europe trial investigators. JAMA 1999; 282: 539-546.

4 Shimada K, Kawamoto A, Matsubayashi K, Ozawa T. Silent cerebrovascular disease in the elderly. Correlation with ambulatory pressure. Hypertension 1990; 16: 692-699.

5 Verdecchia P, Porcellati C, Schillaci G, Borgioni C, Ciucci A, Battistelli M, Guerrieri M, Gatteschi C, Zampi I, Santucci A, Santucci C, Reboldi G. Ambulatory blood pressure. An independent predictor of prognosis in essential hypertension. Hypertension 1994; 24: 793-801.
6 Kario K, Pickering TG, Matsuo T, Hoshide S, Schwartz JE, Shimada K. Stroke prognosis and abnormal nocturnal blood pressure falls in older hypertensives. Hypertension 2001; 38: 852-857.

7 Ohkubo T, Imai Y, Tsuji I, Nagai K, Watanabe N, Minami N, Itoh O, Bando T, Sakuma M, Fukao A, Satoh H, Hisamichi S, Abe K. Prediction of mortality by ambulatory blood pressure monitoring versus screening blood pressure measurements: a pilot study in Ohasama. J Hypertens 1997; 15: 357-364.

8 Ohkubo T, Imai Y, Tsuji I, Nagai K, Watanabe N, Minami N, Kato J, Kikuchi N, Nishiyama A, Aihara A, Sekino M, Satoh H, Hisamichi S. Relation between nocturnal decline in blood pressure and mortality. The Ohasama study. Am J Hypertens 1997; 10: 1201-1207.

9 Ohkubo T, Hozawa A, Yamaguchi J, Kikuya M, Ohmori K, Michimata M, Matsubara M, Hashimoto J, Hoshi H, Araki T, Tsuji I, Satoh H, Hisamichi S, Imai Y. Prognostic significance of the nocturnal decline in blood pressure in individuals with and without high 24-h blood pressure: the Ohasama study. J Hypertens 2002; 20: 2183-2189.

10 DeQuattro V, Lee DD, Allen J, Sirgo M, Plachetka J. Labetalol blunts morning pressor surge in systolic hypertension. Hypertension 1988; 11: I198-I201.

11 Gosse P, Lasserre R, Minifie C, Lemetayer P, Clementy J. Blood pressure surge on rising. $J$ Hypertens 2004; 22: 1113-1118.

12 Muller JE, Stone PH, Turi ZG, Rutherford JD, Czeisler CA, Parker C, Poole WK, Passamani E, Roberts R, Robertson T, Sobel BE, Willerson JT, Braunwald E. Circadian variation in the frequency of onset of acute myocardial infarction. N Engl J Med 1985; 313: $1315-1322$.

13 Muller JE, Ludmer PL, Willich SN, Tofler GH, Aylmer G, Klangos I, Stone PH. Circadian variation in the frequency of sudden cardiac death. Circulation 1987; 75: 131-138.

14 Tsementzis SA, Gill JS, Hitchcock ER, Gill SK, Beevers DG. Diurnal variation of and activity during the onset of stroke. Neurosurgery 1985; 17: 901-904.

15 Kario K, Pickering TG, Umeda Y, Hoshide S, Hoshide Y, Morinari M, Murata M, Kuroda $\mathrm{T}$, Schwartz JE, Shimada K. Morning surge in blood pressure as a predictor of silent and clinical cerebrovascular disease in elderly hypertensives: a prospective study. Circulation 2003; 107: 1401-1406.

16 Metoki H, Ohkubo T, Kikuya M, Asayama K, Obara T, Hashimoto J, Totsune K, Hoshi H, Satoh H, Imai Y. Prognostic significance for stroke of a morning pressor surge and a nocturnal blood pressure decline: the Ohasama study. Hypertension 2006; 47: $149-154$. 
17 Kikuya M, Hansen TW, Thijs L, Bjorklund-Bodegard K, Kuznetsova T, Ohkubo T, Richart T, Torp-Pedersen C, Lind L, Ibsen H, Imai Y, Staessen JA. Diagnostic thresholds for ambulatory blood pressure monitoring based on 10-year cardiovascular risk. Circulation 2007; 115: 2145-2152.

18 Boggia J, Li Y, Thijs L, Hansen TW, Kikuya M, Bjorklund-Bodegard K, Richart T, Ohkubo T, Kuznetsova T, Torp-Pedersen C, Lind L, Ibsen H, Imai Y, Wang J, Sandoya E, O'Brien $E$, Staessen JA. Prognostic accuracy of day versus night ambulatory blood pressure: a cohort study. Lancet 2007; 370: 1219-1229.

19 Li Y, Thijs L, Hansen TW, Kikuya M, Boggia J, Richart T, Metoki H, Ohkubo T, Trop-Pedersen C, Kuznetsova T, Stolarz-Skizypek K, Tikhonoff V, Malyutina S, Casiglia E, Nikitin Y, Sandoya E, Kawecka-Jaszcz K, Ibsen H, Imai Y, Wang J, Staessen J. Prognostic value of the morning blood pressure surge in 5645 subjects from 8 populations. Hypertension 2010; 55: 1040-1048.

20 Fagard RH, Staessen JA, Thijs L. Prediction of cardiac structure and function by repeated clinic and ambulatory blood pressure. Hypertension 1997; 29: 22-29.

21 Ohkubo T, Asayama K, Kikuya M, Metoki H, Hoshi H, Hashimoto J, Totsune K, Satoh H, Imai $Y$. How many times should blood pressure be measured at home for better prediction of stroke risk? Ten-year follow-up results from the Ohasama study. J Hypertens 2004; 22: 1099-1104.

22 Metoki H, Ohkubo T, Kikuya M, Asayama K, Obara T, Hara A, Hirose T, Hashimoto J, Totsune K, Hoshi H, Satoh H, Imai Y. Prognostic significance of night-time, early morning, and daytime blood pressures on the risk of cerebrovascular and cardiovascular mortality: the Ohasama Study. J Hypertens 2006; 24: 1841-1848.

23 Kikuya M, Ohkubo T, Asayama K, Metoki H, Obara T, Saito S, Hashimoto J, Totsune K, Hoshi H, Satoh H, Imai Y. Ambulatory blood pressure and 10-year risk of cardiovascular and noncardiovascular mortality: the Ohasama study. Hypertension 2005; 45: 240-245.

24 Ohkubo T, Hozawa A, Nagai K, Kikuya M, Tsuji I, Ito S, Satoh H, Hisamichi S, Imai Y. Prediction of stroke by ambulatory blood pressure monitoring versus screening blood pressure measurements in a general population: the Ohasama study. J Hypertens 2000; 18: 847-854.
25 Shintani Y, Kikuya M, Hara A, Ohkubo T, Metoki H, Asayama K, Inoue R, Obara T, Aono Y, Hashimoto T, Hashimoto J, Totsune K, Hoshi H, Satoh H, Imai Y. Ambulatory blood pressure, blood pressure variability and the prevalence of carotid artery alteration: the Ohasama study. J Hypertens 2007; 25: 1704-1710.

26 Aono Y, Ohkubo T, Kikuya M, Hara A, Kondo T, Obara T, Metoki H, Inoue R, Asayama K, Shintani Y, Hashimoto J, Totsune K, Hoshi H, Satoh H, Izumi S, Imai Y. Plasma fibrinogen, ambulatory blood pressure, and silent cerebrovascular lesions: the Ohasama study. Arterioscler Throm Vasc Biol 2007; 27: 963-968.

27 Nakashita M, Ohkubo T, Hara A, Metoki H, Kikuya M, Hirose T, Tsubota-Utsugi M, Asayama K, Inoue R, Kanno A, Obara T, Hoshi H, Totsune K, Satoh H, Imai Y. Influence of alcohol intake on circadian blood pressure variation in Japanese men: the Ohasama study. Am J Hypertens 2009; 22: 1171-1176.

28 Kikuya M, Sugimoto K, Katsuya T, Suzuki M, Sato T, Funahashi J, Katoh R, Kazama I, Michimata M, Araki T, Hozawa A, Tsuji I, Ogihara T, Yanagisawa T, Imai Y, Matsubara M. A/C1166 gene polymorphism of the angiotensin II type 1 receptor (AT1) and ambulatory blood pressure: the Ohasama Study. Hypertens Res 2003; 26: 141-145.

29 Fujiwara T, Katsuya T, Matsubara M, Mikami T, Ishikawa K, Kikuya M, Ohkubo T, Hozawa A, Michimata M, Suzuki M, Metoki H, Asayama K, Araki T, Tsuji I, Higaki J, Satoh H, Hisamichi S, Ogihara T, Imai Y. T+31C polymorphism of angiotensinogen gene and nocturnal blood pressure decline: the Ohasama study. Am J Hypertens 2002; 15: 628-632.

30 Matsubara M, Kikuya M, Ohkubo T, Metoki H, Omori F, Fujiwara T, Suzuki M, Michimata M, Hozawa A, Katsuya T, Higaki J, Tsuji I, Araki T, Ogihara T, Satoh H, Hisamichi S, Nagai K, Kitaoka H, Imai Y. Aldosterone synthase gene (CYP11B2) C-334 T polymorphism, ambulatory blood pressure and nocturnal decline in blood pressure in the general Japanese population: the Ohasama Study. J Hypertens 2001; 19: 2179-2184.

31 Hirose T, Hashimoto M, Totsune K, Metoki H, Asayama K, Kikuya M, Sugimoto K, Katsuya T, Ohkubo T, Hashimoto J, Rakugi H, Takahashi K, Imai Y. Association of (pro)renin receptor gene polymorphism with blood pressure in Japanese men: the Ohasama study. Am J Hypertens 2009; 22: 294-299. 